\title{
Recommender system to identify students with learning deficiencies in assessments
}

\author{
Manuel J. Ibarra, Cristhian Serrano \\ School of Informatics and Systems Engineering \\ Micaela Bastidas National University of Apurímac \\ Apurimac, Peru \\ \{manuelibarra, cristhiansj\}@gmail.com
}

\begin{abstract}
Find areas and indicators of achievement where students need to reinforce their knowledge is a difficult task for teachers in schools. This article presents a decision-making support system that allows teachers to identify students with poor academic performance. The strategy is a Matrix Based Recommender System to rate assessments and share the results using statistical graphs. To validate this proposal we used focus group and daily meetings methodologies. The proposed strategy was tested in UGEL07-Lima-Perú with 135 schools and 25491 students in evaluation process. The evaluation results show that teachers agree with the proposed strategy, because it allows them to have assessment information everywhere and at every time. The results also highlight that using the tool users can have visual information in real time. Furthermore, the information shared through the application improves decision-making on corrective actions for poor academic performance in evaluated areas.
\end{abstract}

Keywords-Learning Assessment, Decision Making, Data Visualization, Recommender System, Excel VBA

\section{INTRODUCTION}

The Education Act No 23384 governs education in Peru; it is based on the principle of social democracy, which means that everyone has the right to get an education that will contribute to their development.

Each school (IE: Institución Educativa in Spanish) management focuses on "Eight Commitments School Management", considered integral to ensure the students learning. These commitments are expressed in terms of "Indicators" that can identify the IEs that need to intervene, providing the educational community relevant information for decisions making aimed at improving learning. As indicated by the School Management Manual, "the actions of the IE focuses on these commitments, aimed at ensuring progress in learning, retention and completion of the school year (ending) through an agreed plan a favorable climate and a process of support to the teaching practice" [1]. The first commitment mentioned "Annual Progress learning of each and every student of the school", this is one of the more important commitments to improve student's learning process.

To meet the first commitment the IE organize and propose periodically assessments for students; it means, they implement an evaluation culture for students and propose corrective measures for poor academic student performance in the evaluated areas and schools. According to Gonzales et al. [2], an evaluation culture could be defined as the set of values,

\author{
Ángel F. Navarro \\ School of Systems Engineering, \\ Jose Maria Arguedas National University of Apurímac \\ Apurimac, Peru \\ \{angelnr22\}@gmail.com
}

agreements, traditions, beliefs and thoughts that an educational community attaches to the action of evaluation. Bolseguí and Fuguet [3] point out that the assessment is a complex and multidimensional process that includes different components: vision, values, behaviors, routines, organizational and social context, past and present experiences, epistemological, theoretical and methodological.

Organizational complexity is very high because the evaluation processes and functions require multi-system collaboration, and has a high reliance on effective information communication among UGEL(in Spanish Unidad de Gestión Educativa), IE, Director, Teachers and therefore faces many challenges regarding pragmatic interoperability such as information collision, policy obstacles, and procedure mismanagement.

Once evaluated, it is necessary to analyze and interpret the results, also is important that data are properly displayed; this topic has been widely discussed by the authors in the area of data visualization [4][5]. Most frequently, a key feature of such an approach is showing relationships between different data groups of a provided statistical selection: in order to compare relative proportions between various indicators [6] [7].

This article presents a strategy to qualify student test primary and secondary level in Math, Communication, Social and Science areas in Educational Institutions of UGEL07, LimaPeru. The system show the obtained results by statistical charts sharing achievement levels for each student, this information is useful to teachers who can use improvement strategies for underperforming students. In addition, the tool also allows you to display statistical graphs of the results by district, by level, by grade, by area; with this information Directors of UGEL and IE can make decisions to improve student learning.

Section II of this article presents and discusses the works related to recommender system, learning analytics and data visualization; section III explains the design and implementation of the proposed strategy; section IV explains the evaluation methodology used to validate the proposed strategy; finally, section $\mathrm{V}$ describes the conclusions and future work.

\section{RELATED WORKS}

Recommender systems are used for both discovery and filtering assessment data in applications, to assist users in locating interesting information: best students, complicated questions and prioritize information for decision making. 
Matrix Factorization are used for Recommender Systems [8] as the Netflix Prize competition has demonstrated, matrix factorization models are superior to classic nearest-neighbor techniques for producing product recommendations, allowing the incorporation of additional information such as implicit feedback, temporal effects, and confidence levels.

Aciar et al. [9] uses consumer product reviews for recommendation and is based on computing the qualities of the features of products, from aggregating reviewers' opinions on these features weighted by the level of reviewers' expertise. User queries of the form "I would like to know if Sony W70 is a good camera, specifically its interface and battery consumption" are required at the input of the presented recommender system. A similar system is presented by Kuroiwa [10]. Since both systems aggregate all opinions on a single item or on its features to one score, neither provides personalized recommendations.

Learning Analytics Dashboards can be considered as a specific class of "personal informatics" applications [11]. These typically support users in collecting personal information about various aspects of their life, behavior, habits, thoughts, and interests [12]. Personal informatics applications help users to improve self-knowledge by providing tools for the review and analysis of their personal history. Self-knowledge has many benefits, such as fostering insight, increasing self-control [13] and promoting positive behavior [14]. Verbert et al. [15] made a research titled "Learning Analytics Dashboard Applications", the article proposes learning analytics dashboards that visualize learning traces for learners and teachers, they made a conceptual framework that helps to analyze learning analytics applications for these kinds of users, then they present their own work in this area and compare with 15 related dashboard applications for learning. [16] Martinez et al investigated the "The LATUX workflow: Designing and deploying awareness tools in technology-enabled learning settings" they present a five-stage workflow to design, deploy and validate awareness tools in technology-enabled learning environments.

Data visualization is a general term that describes any effort to help people understand the significance of data by placing it in a visual context. There are techniques for facilitating data selection in the data transformation process [17][18], techniques for selecting chart type and visual components (e.g., line style, point face, axis range) automatically in the visual mapping process [19][20]; and techniques for changing visual effects to clarify the user's viewpoint and assertion easily [21] in the view transformation process. Matsushita et al. [22] made a research titled "Interactive Visualization Method for Exploratory Data Analysis". They propose an interactive visualization method suitable for exploratory data analysis.

\section{The Proposed Strategy}

Let's consider the following real-world example from the data used in our experiments of Indicators and Weighing provided on items in the Table I: The column "Capacity" represents the ability that the students have to acquire after evaluations; "Indicators of Performance" represents the way of measure of the learning process; "Number of Question" represents the number of items for assessment; "Correct
Answer" Is the correct answer of three possible alternatives (A, $\mathrm{B}$ or C) and "Weighing" represents the weighting assigned to each question.

TABLE I. INDICATORS AND WEIGHING FOR SECONDARY LEVEL, FIRST GRADE IN COMMUNICATION AREA

\begin{tabular}{|c|c|c|c|c|}
\hline Capacity & Indicators of Performance & $\begin{array}{c}\text { Number } \\
\text { of } \\
\text { Question }\end{array}$ & $\begin{array}{l}\text { Correct } \\
\text { Answer }\end{array}$ & Weighing \\
\hline \multirow{11}{*}{$\begin{array}{l}\text { Infers the } \\
\text { meaning of } \\
\text { written texts }\end{array}$} & $\begin{array}{l}\text { Deduce the characteristics } \\
\text { and qualities of characters, } \\
\text { when is a suggested text }\end{array}$ & 7 & $\mathrm{C}$ & 1 \\
\hline & \multirow{2}{*}{ Deduce the purpose of a text } & 3 & B & 1 \\
\hline & & 8 & A & 1 \\
\hline & \multirow{3}{*}{$\begin{array}{l}\text { Deduces the meaning of } \\
\text { words, phrases and } \\
\text { sentences with double } \\
\text { meaning and figuratively } \\
\text { from explicit information. }\end{array}$} & 2 & $\mathrm{C}$ & 1 \\
\hline & & 10 & $\mathrm{~A}$ & 1 \\
\hline & & 19 & B & 1 \\
\hline & \multirow{3}{*}{$\begin{array}{l}\text { Explains the intention of the } \\
\text { author of the story }\end{array}$} & 9 & $\mathrm{C}$ & 1.5 \\
\hline & & 12 & $\mathrm{~B}$ & 1.5 \\
\hline & & 17 & $\mathrm{~A}$ & 1.5 \\
\hline & \multirow{2}{*}{ Infers cause-effect } & 13 & $\mathrm{C}$ & 1.5 \\
\hline & & 18 & A & 1.5 \\
\hline \multirow{3}{*}{$\begin{array}{l}\text { Reflects on the } \\
\text { form, content, } \\
\text { and context of } \\
\text { the texts }\end{array}$} & \multirow{3}{*}{$\begin{array}{l}\text { Review the purpose of the } \\
\text { author of the news }\end{array}$} & 4 & B & 1.5 \\
\hline & & 20 & $\mathrm{~A}$ & 1.5 \\
\hline & & 14 & $\mathrm{C}$ & 1.5 \\
\hline \multirow{6}{*}{$\begin{array}{l}\text { Retrieves } \\
\text { information } \\
\text { from various } \\
\text { written texts }\end{array}$} & \multirow{3}{*}{ Identify type of text } & 6 & $\mathrm{C}$ & 0.5 \\
\hline & & 11 & $\mathrm{~A}$ & 0.5 \\
\hline & & 16 & $\mathrm{~B}$ & 0.5 \\
\hline & \multirow{3}{*}{$\begin{array}{l}\text { Locate relevant information } \\
\text { in the read text }\end{array}$} & 1 & $\mathrm{~A}$ & 0.5 \\
\hline & & 5 & $\mathrm{C}$ & 0.5 \\
\hline & & 15 & $\mathrm{~B}$ & 0.5 \\
\hline
\end{tabular}

\section{A. The Recommendation Process}

The system uses a decision matrix to address multiple criteria and variables in order to analyze the Questions and Indicators for each evaluated area: Mathematics, Communication, Social and Science. The recommendation process has the following steps:

- The UGEL's Director plans the schedule of the exams.

- The UGEL's Director plans the areas (Mathematics, Communication, Social, and Science) and levels (Primary and Secondary) to be evaluated.

- The Education Specialists prepare de Evaluation Matrix:

- Provides the number of questions (20 questions) and their indicators for each question.

- Provides the weighting factor for each question $(0.5$ points, 1 point, 1.5 points).

- Provides the correct Answer for each question.

- The Education Specialists register in the System the Evaluation Matrix.

- The System process de Evaluation Matrix and perform the rating for each question and each student.

- The System creates and display the Recommendations based on the Evaluation Matrix.

\section{B. Matrix Based Recommender System}

Let $\boldsymbol{Q T}$ be a Matrix of order $m X n$, where $m$ : represents the number of students in a grade and section and $n$ represents the number of questions of the assessment; $q_{1}, q_{2}, \ldots, q_{n}$ represents each question; $t_{1}, t_{2}, \ldots, t_{m}$ represents each student; " 0 " means 
Manuel J. Ibarra, Cristhian Serrano, Ángel F. Navarro. Recommender system to identify students with learning deficiencies in assessments

that the student answered incorrectly and " 1 " means that the student answered correctly the question, as follows.

$$
Q T_{(m X n)}=\left[\begin{array}{rrrrrrr}
q_{1} & q_{2} & q_{3} & q_{4} & q_{5} & \cdots & q_{n} \\
1 & 1 & 1 & 1 & 1 & \cdots & 1 \\
1 & 0 & 0 & 1 & 1 & \cdots & 0 \\
1 & 1 & 1 & 1 & 0 & \cdots & 0 \\
0 & 1 & 1 & 0 & 1 & \cdots & 0 \\
t_{2} \\
\vdots & \vdots & \vdots & \vdots & \vdots & \cdots & \vdots \\
1 & 0 & 1 & 0 & 1 & \cdots & 0
\end{array}\right]_{t_{3}}
$$

Let $\boldsymbol{W}$ be a Matrix of order $1 X n$, where $n$ : represents the number of questions and $w_{1}, w_{2}, \ldots, w_{n}$ represents each weighing for each question; for example, question $q_{1}$ has a weighing of 0.5 ; question $q_{2}$ has a weighing of 1 , question $q_{n}$ has a weighing of 1 , as shown in (2).

$$
W=\left[\begin{array}{ccccccc}
w_{1} & w_{2} & w_{3} & w_{4} & w_{5} & \cdots & w_{n} \\
0.5 & 1 & 1 & 1.5 & 0.5 & \cdots & 1
\end{array}\right]
$$

Then, we multiply each row of QT Matrix by the row of weighing $\boldsymbol{W}$ Matrix. Finally, we have a $\boldsymbol{R}$ Matrix with one column added that represents the total punctuation obtained by each student; for example, first student has a punctuation of $0+1+1+1.5+0.5+1=5$. Moreover, $\boldsymbol{R}$ Matrix has one row added that represents the count of each question that was correctly answered by the students; for example, the first question has 3 students that marked correctly the answer, as shown in (3).

$R_{(m+1 \times n+1}=\left[\begin{array}{ccccccc:c}0 & 1 & 1 & 1.5 & 0.5 & \cdots & 1 & 5 \\ 0.5 & 0 & 0 & 1.5 & 0.5 & \cdots & 0 & 2.5 \\ 0.5 & 1 & 1 & 1.5 & 0 & \cdots & 0 & 4 \\ 0 & 1 & 1 & 0 & 0.5 & \cdots & 0 & 2.5 \\ \vdots & \vdots & \vdots & \vdots & \vdots & \cdots & \vdots & \\ 0.5 & 0 & 1 & 0 & 0.5 & \cdots & 0 & 2 \\ \hdashline 3 & 3 & 4 & 3 & 4 & \cdots & 1 & \end{array}\right](3)$

The column $(n+l)$ is important, because it is the final punctuation for each student, and the teacher will have to decide the strategy to improve the acknowledge of them. The row $(m+l)$ is important because it is the number students who solved correctly the question.

Let $S Q$ be a Matrix of order $1 X n$, where $n$ : represents the number of Strategies proposed for questions; and $s q_{1}, s q_{2}, \ldots, s q_{n}$ represents each Strategy for each question; for example, $s q_{1}$ has a strategy for question $q_{1} ; s q_{2}$ has a strategy for question $q_{2}$, as shown in (4)

$$
S Q=\left[\begin{array}{lllllll}
s q_{1} & s q_{2} & s q_{3} & s q_{4} & s q_{5} & \cdots & s q_{n}
\end{array}\right]
$$

Let $S T$ be a Matrix of order $k X 1$, where $k$ : represents the number of strategies proposed for students; and $s t_{1}, s t_{2}, \ldots, s t_{k}$ represents each Strategy to by applied to students; for example, $s t_{1}$ has a strategy for students who reached the "Initiation" level; $s t_{2}$ has a strategy for students who reached the "In Process" level and $s t_{k}$ has a strategy for students who reached the "Achieved" level, as shown in (5).

$$
S T=\left[\begin{array}{c}
s t_{1} \\
s t_{2} \\
\vdots \\
s t_{k}
\end{array}\right]
$$

For example, in question $q_{n}$ only one student answered correctly, so in this case, the Strategy $s q_{n}$ has to be applied to improve the level of success of the question (probably question was understandable or very difficult for students). Likewise, student $t_{m}$ has obtained only 2 points in all answered questions of the assessment (Initiation level), so in this case the Strategy $s t_{1}$ has to be applied to improve the student knowledge (probably change learning methodology or change type of exercises)

\section{System Architecture}

The DRE's server stores the operational data in Mysql database, data is related to each assessment, student's attribute, the answers marked by the student, the Indicators of each question and so for, it is called the Data Tier. In the Business Tier is located the Web server, which stores php pages and procedures to optimize queries. Presentation Tier shows the Excel File that Teacher will use to fill out the student's marked answers, then, clicking in a button graphs are activated and updated; then clicking other button, data will be export to "csv" file and send to database; also, the System uses HTML, CSS and JavaScript to decorate and validate webpages of the client side. Fig. 1. shows logical architecture of the proposed tool.

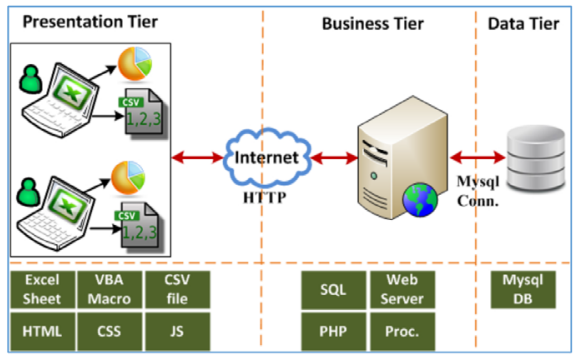

Fig. 1. System architecture

\section{Algorithm to process data}

To process data and optimize resources, we use an algorithm to rate assessments. It starts having an Excel file as an Input, then, variables are declared. The first loop through each grade, the second loop through section and the third loop through each student's data. Then data is exported to csv file and send to the server, this stage is important because the speed of internet some areas of Lima is quite slow. The complete algorithm is shown in Fig. 2.

\begin{tabular}{|l|}
\hline Program Assessment; \\
//INPUT:Excel File \\
var \\
listGrades:List; //first,Second,...,Sixth \\
listSections:List; //A,B,C,D... \\
listStudents:List;//name \\
correctAns:List //A,B,A,C,B,..., C \\
altMarked:List //A,A,C,A,C,..,C \\
\hline
\end{tabular}




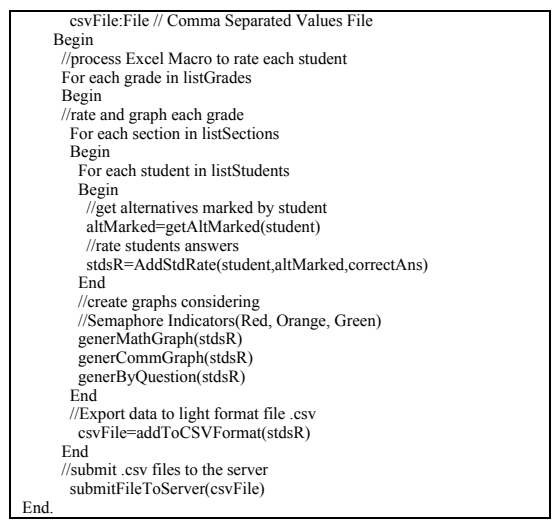

Fig. 2. Algorithm to process data

\section{E. Input and data visualization}

An Excel File was designed to fill the answers marked by students, as shown in Fig 3. Every question can be marked with "A", "B", "C", "X" (when students mark two or more answers) or " " (blank, when a student did not mark any answer). Mathematics, Communication, Social and science have 20 questions, every section has from one to forty-five students approximately and in the primary level has six grades and in the secondary level has five grades.

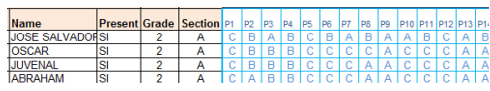

Fig. 3. Sheet to fill answers

Assigning Reached Level. Each test has 20 questions for each area. To determine the level reached by a student, specialists produce distribution of scores, as shown in Table II. For example, if a student gets a score of 5 , then, the level acquired is "Initiation"; if a student gets a score of 12 , then, the level acquired is "In Process"; and if a student gets a score of 20 , then, the level acquired is "Achieved".

TABLE II. DISTRIBUTION OF REACHED LEVEL ACCORDING TO PUNCTUATION AND COLOR ASSIGNED

\begin{tabular}{|c|c|c|c|c|}
\hline Item & Reached level & Punctuation & Color & Description \\
\hline 0 & Initiation & $0-10.4$ & $\bigcirc$ & Red \\
\hline 1 & In Process & $10.5-13.4$ & $\bigcirc$ & Orange \\
\hline 2 & Achieved & $13.5-20$ & $\bigcirc$ & Green \\
\hline
\end{tabular}

\section{Example of data visualization}

After the teacher fill out the answers, the system uses functions in Excel Macro to rate the assessment. The report shows the number of questions successes by student, for example, student named Ccañahua has nine success questions in Communication area, so the semaphore indicator is red; student named Chiclla has fourteen success questions in Communication area, so the semaphore indicator is green; and Gutierrez has eleven success questions, so the semaphore indictor is orange, see Table III.

TABLE III. STUDENT'S REACHED LEVEL AND SEMAPHORE INDICATOR

\begin{tabular}{|l|r|c|l|}
\hline Name & $\begin{array}{l}\text { Punctuation } \\
\text { (max.20) }\end{array}$ & $\begin{array}{l}\text { Semaphore } \\
\text { Indicator }\end{array}$ & Strategy \\
\hline Ccañahua & 9 & $\bigcirc$ & Strategy 3 \\
\hline Chiclla & 14 & $\bigcirc$ & Strategy 1 \\
\hline Gutierrez & 11 & $\bigcirc$ & Strategy 2 \\
\hline Huachaca & 17 & $\bigcirc$ & Strategy 1 \\
\hline
\end{tabular}

Other data visualization is "Results by question", in this case the system shows the results in bar type graph, in the "Y" axis shows the number of students that answered correctly the question; in the " $\mathrm{X}$ " axis the system shows the label for the "number of question", "Q1" represents Question 1, "Q2" represents Q2 and so forth. For example, in "Q1" sixteen students answered correctly for Communication Area, in second grade, in primary level, in 2015. See Fig 4.

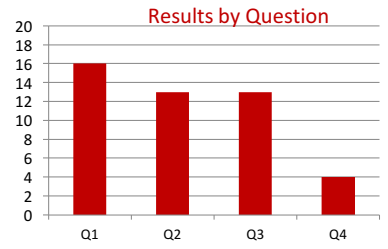

Fig. 4. Results for Communication Area, second grade, 2015

\section{Dynamic reports for UGEL, District, Level and Grade}

Dynamic report web tool was designed to facilitate client's work. Fig. 5 shows the interface to select options for and then execute the report. All options in the combo box are automatically filled by the system according with the data stored in the database. For example, Fig. 5 shows the report for year 2015, for primary level, for Communication area and first grade.

With the selected options, the system process data and then the user has two options to see the report: in "screen" and in "excel format". Either in screen an excel mode, the user then can print the obtained results. 


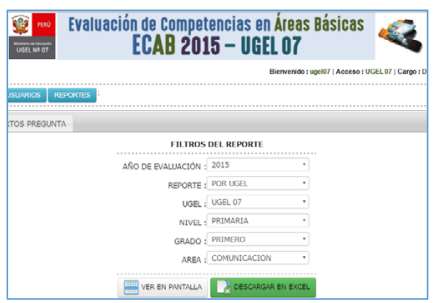

Fig. 5. Options of report

The system receives the petition and then process the query and finally shows the report as shown in Fig. 6. This report has two parts, the first one shows the processed data in "table mode" and the second one in cake graph.

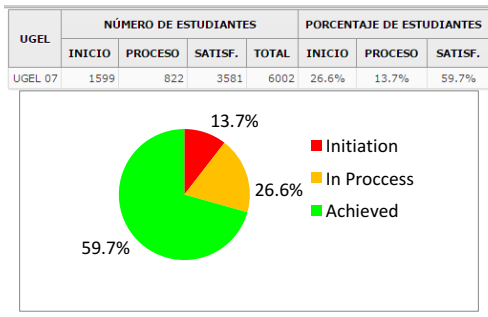

Fig. 6. Report visualization

\section{EVAluATION OF THE PROPOSED STRATEGY}

The validation of the tool was conducted with Education Specialist (workers) of UGEL07 through a focus group. The event took place on: Dec 21, Jan 11 and Jan 25, 2015, in a meeting room of the Management of Basic and Special Education Area (AGEBRE in Spanish) of UGEL07 in Lima. The participants were three specialists in educational evaluation. All participants have significant years of experience in monitoring and supervising educational schools.

Before starting the activity, the developed system was briefly shown to each specialist in evaluation. A simulation of the software functionality was then done. An operator, using the system, entered the "modular code" of the IE, then, the System generates the list of students of each grade and sections. The specialist fill out the answers for each student and then the system shows the results graphically, then, he exports the result to CSV file and finally sends information to the datacenter.

After this simulated process, the Education Specialists provided feedback, suggestions and opinions, and agreed that the system can definitely help improve decision making and perception (awareness) of the assessment results. When asked: "will the use of the designed software help you to make it easier the data visualization of evaluation assessment results?" they all answered that in their opinion that assumption was valid. Then they were asked: "would the decision-making speed and quality of decisions have been better if the Director would have had a support tool that is visual and provides the appropriate suggestions?", they all replied that a positive answer would be valid, the Education Specialists indicated that they have Semaphore Indicators to help them make decisions more quickly, and probably also better ones.

There was one assessment supported by the proposed tool, it was made in 2015, in which participated 135 schools and 25491 students (81 schools with 12820 students in Primary level and 54 schools with 12671 students in Secondary level).

\section{CONCLUSIONS AND FUTURE WORK}

In this paper we present a Matrix Based Recommender System to identify students with deficiencies in learning assessments for Education Environment, it is based on indicators, weighing and strategies assigned by Specialist of the UGEL07 in Lima Peru. We proposed a tool based on an Excel File in which the evaluator fills the answers marked by students, then, the System uses the Recommender Matrix to rate each question and show various reports with the processed information. Specialists agreed that having this type of information in the Recommender system would help to know the levels reached (Beginning, In Process, and Achieved) by students in every area, level, grade and district; also, Director could have accurate information when making decisions based on the learning achievement indicators.

The time required to have results of the assessment is reduced significantly and the information is available at every time and everywhere whenever Internet connection is available. Likewise the participant Specialists agreed that, a priori, they can expect a significant improvement in the process of student learning rating and the quality of decisions, because Directors would have accurate information when making decisions.

In the future, we aim to develop more functionality and evaluate the user interfaces to improve the tool. Moreover, the system will be tested in other Regions of Peru.

\section{ACKNOWLEDGEMENTS}

Thanks to the Education Specialists of AGEBRE of the UGEL07 in Lima Peru, especially Fredy Villarroel and William Pachas.

\section{REFERENCES}

[1] http://www.minedu.gob.pe/campanias/pdf/manual-de-gestion-escolar2015_10marzo_alta.pd (last visited 5 February 2016)

[2] González, JR., Soledad, M., Montoya, R., Rivera, JA.: Cultura de evaluación en instituciones educativas. Perfiles Educativos; vol.33 num.131, pp.42-63 (2011)

[3] Bolsegui, M., A. Fuguet, A.: "Cultura de evaluación: una aproximación conceptual”, Investigación y Postgrado, vol. 21, num.1, pp. 77-98 (2006)

[4] Guchev, V., Massimo, M., Giuseppe S.: Design guidelines for correlated quantitative data visualizations. Proceedings of the International Working Conference on Advanced Visual Interfaces. ACM (2012)

[5] Keim, D., Kohlhammer, J., Ellis, G., Mansmann, F.: Mastering the Information Age: Solving Problems with Visual Analytics. Eurographics Association (2010)

[6] Spence, R.: Information Visualization: Design for Interaction. Pearson Educational Limited (2007)

[7] Wilkinson, L.: The Grammar of Graphics. Springer Verlag New York, Second Edition (2005) 
[8] Koren, Y., Bell, R., Volinsky, C. : Matrix factorization techniques for recommender systems. Computer, (8), 30-37 (2009)

[9] Aciar, S., Zhang, D., Simoff, S., Debenham, J.: Informed Recommender: Basing Recommendations on Consumer Product Reviews. IEEE Intelligent Systems 22, 3 (2007)

[10] Kuroiwa, T., Bhalla, S.: Aizu-BUS: need-based book recommendation using web reviews and web services. In: Bhalla, S. (ed.) DNIS 2007. LNCS, vol. 4777, pp. 297-308. Springer, Heidelberg (2007)

[11] Li, I., Dey, A., Forlizzi, J.: A stage-based model of personal informatics systems. In Proceedings of CHI10: 28th International Conference on Human Factors in Computing Systems (pp. 557-566). New York, NY: ACM (2010)

[12] Li, I., Dey, A., Forlizzi, J., Höök, K., Medynskiy, Y.: Personal informatics and HCI: Design, theory, and social implications. In Proceedings of the 2011 Annual Conference on Human Factors in Computing Systems, CHI EA '11 (pp. 2417-2420). New York, NY: ACM. doi:10.1145/1979482.1979573 (2011)

[13] O'Donoghue, T., Rabin, M.: Self-awareness and self-control. Time and decision: Economic and psychological perspectives on intertemporal choice. New York, NY: Russell Sage Foundation (2003)

[14] Seligman, C., Darley, J.: Feedback as a means of decreasing residential energy consumption. Journal of Applied Psychology, vol.62 num.4, pp.363-368 (1977)
[15] Verbert, K., Duval, E., Klerkx, J., Govaerts, S., Santos, J. L.: Learning analytics dashboard applications. American Behavioral Scientist, 0002764213479363. ISO 690 (2013)

[16] Martinez-Maldonado, R., Pardo, A., Mirriahi, N., Yacef, K., Kay, J. and Clayphan, A.: The LATUX workflow: Designing and deploying awareness tools in technology-enabled learning settings. Proceedings of the Fifth International Conference on Learning Analytics and Knowledge. ACM (2015)

[17] Ahlberg, C., Shneiderman, B.: Visual information seeking: Tight coupling of dynamic query filters with starfield displays. Proceedings of the SIGCHI conference on Human factors in computing systems. ACM (1994)

[18] Derthick, M., Harrison, J., Moore, A., Roth, S.F.: Efficient multi-object dynamic query histograms. In Information Visualization Proceedings. IEEE Symposium on (pp. 84-91) (1999)

[19] Mackinlay, J. D.: Automating the design of graphical presentations of relational information. Readings in intelligent user interfaces (1998)

[20] Fasciano, M., Lapalme G. : Postgraphe: a system for the generation of statistical graphics and text. Proceedings of the Eighth International Workshop on Natural Language Generation (1996)

[21] Mittal, V. O.: Visual prompts and graphical design: A framework for exploring the design space of 2-D charts and graphs. AAAI/IAAI (1997)

[22] Matsushita, M., Kato T.: Interactive visualization method for exploratory data analysis. Information Visualisation. Proceedings. Fifth International Conference on. IEEE (2001) 